\title{
Crise, condicionantes e desafios de coordenação do Estado federativo brasileiro no contexto da COVID-19
}

\author{
Crisis, conditioning factors, and challenges in \\ the coordination of Brazil's federative State \\ in the context of COVID-19
}

\section{Crisis, condicionantes y desafíos de coordinación del Estado federativo brasileño en el contexto de la COVID-19}

\author{
Luciana Dias de Lima 1 \\ Adelyne Maria Mendes Pereira 1,2 \\ Cristiani Vieira Machado 1
}

doi: 10.1590/0102-311X00185220

\section{Introdução}

A pandemia de COVID-19, ao atingir o Brasil, acentua o cenário de instabilidade política, econômica e social que vinha marcando o país desde 2015. No âmbito político-institucional, revela-se uma crise de coordenação, de forte dimensão federativa, que se manifesta de forma diversa nas políticas públicas: entraves de articulação intergovernamental; indefinição e sobreposição de atribuições e funções; dificuldades de execução e integração de ações e serviços em tempo oportuno; protagonismo de alguns governos e negligência e omissão de outros; insuficiente transparência e informações contraditórias sobre a COVID-19.

Com o agravamento da pandemia e o colapso do sistema de saúde em várias cidades, os embates entre o presidente da República, governadores e prefeitos tornaram-se progressivamente mais evidentes e acirrados, prejudicando a capacidade de resposta do Estado e gerando descrédito e insegurança na população. No início de junho de 2020, o Brasil apresentava o segundo maior número de casos e de óbitos do mundo, atrás apenas dos Estados Unidos 1.

Esse artigo tem como objetivo extrair reflexões da crise do Estado federativo brasileiro, procurando contribuir para a compreensão dos condicionantes e desafios da coordenação de políticas públicas e do Sistema Único de Saúde (SUS) no contexto da COVID-19. Dois argumentos principais norteiam a elaboração do manuscrito.

O primeiro é que os fatores que constrangem a atuação do Estado em sua dimensão federativa são de natureza diversa e têm origem anterior ao surgimento da pandemia. Embora as tensões políticas agudizadas com a COVID-19 sejam relevantes, ressaltamos outros aspectos de natureza político-institucional (características do arranjo federativo) e histórico-estrutural (desigualdades socioespaciais) que também limitam a articulação e o desempenho dos governos.

O segundo está relacionado à necessidade de integração entre áreas da política pública e da articulação entre governos para o desenvolvimento de medidas mais efetivas de mitigação dos danos sociais, econômicos e sanitários decorrentes da COVID-19. Frente à própria dinâmica da pandemia, estratégias e instrumentos de coordenação, envolvendo múltiplas dimensões, atores e escalas de decisão e ação, são essenciais para a implantação de políticas e ações mais abrangentes e integradas.
1 Escola Nacional de Saúde Pública Sergio Arouca, Fundação Oswaldo Cruz, Rio de Janeiro, Brasil. 2 Universitat de les Illes Balears, Palma, España.

Correspondência L. D. Lima Departamento de Administração e Planejamento em Saúde, Escola Nacional de Saúde Pública Sergio Arouca, Fundação Oswaldo Cruz. Rua Leopoldo Bulhões 1480, sala 715, Rio de Janeiro, RJ 21041-210, Brasil. luciana@ensp.fiocruz.br 


\section{Condicionantes da crise federativa do Estado}

Três grupos de condicionantes ajudam na compreensão das dificuldades de resposta do Estado brasileiro no contexto da COVID-19, sob a perspectiva da federação: a especificidade do seu arranjo federativo; a existência de profundas desigualdades socioespaciais; e o acirramento de conflitos políticos entre os governos.

A literatura sobre o federalismo no país é vasta, entretanto há convergências entre os autores no que tange aos seus traços constitutivos, nas dimensões política, fiscal e administrativa 2,3,4, sistematizadas no Quadro 1. Em conjunto, tais aspectos constrangem a atuação do Estado na pandemia, pois configuram um processo decisório complexo e assimétrico, com desigualdades, dificuldades administrativas e forte dependência política e financeira de estados e municípios em relação ao governo federal.

Outro grupo de condicionantes está relacionado às profundas desigualdades socioespaciais, historicamente determinadas, que demarcam o território brasileiro e se expressam em diferentes dimensões, em termos de indicadores econômicos, sociais, acesso à infraestrutura e a serviços de diferentes tipos, inclusive os de saúde. É possível identificar discrepâncias entre as regiões do país - entre os eixos Sudeste-Sul e Norte-Nordeste - bem como entre áreas urbanas e rurais, e no interior das regiões metropolitanas (entre áreas centrais e periféricas, ou no interior das grandes cidades) que impactam na demanda e dificultam a assistência requerida pela COVID-19 5. Há também distintas "situações geográficas" no território brasileiro, com dinamismos econômicos e socioespaciais variados, que têm implicações para o sistema de saúde e precisam ser consideradas no planejamento regional de estratégias de enfrentamento da pandemia 6.

\section{Quadro 1}

Características do arranjo federativo brasileiro com implicações para a coordenação de políticas públicas e do Sistema Único de Saúde (SUS).

\begin{tabular}{|c|c|c|}
\hline POLÍTICA & FISCAL & ADMINISTRATIVA \\
\hline $\begin{array}{l}\text { Organização trina com predomínio de cultura } \\
\text { política centralizadora. } \\
\text { Papel de destaque do Executivo Federal, } \\
\text { vis-à-vis aos demais Poderes de Estado } \\
\text { e esferas de governo. } \\
\text { Ampla autoridade jurisdicional da União e } \\
\text { limitações do exercício de poder de veto das } \\
\text { unidades subnacionais nas arenas nacionais. } \\
\text { Diversidade de instituições e atores } \\
\text { governamentais nos planos nacional e } \\
\text { subnacional. } \\
\text { Assimetria de riqueza e poder político entre } \\
\text { entes de diferentes esferas governamentais. } \\
\text { Pulverização e oligarquização do poder } \\
\text { político loco-regional. }\end{array}$ & $\begin{array}{l}\text { Tributação regressiva, com centralização da } \\
\text { arrecadação na União e descentralização da } \\
\text { execução orçamentária. } \\
\text { Predomínio de relações fiscais verticais (do } \\
\text { governo federal para os entes subnacionais). } \\
\text { Sistema de partilha fiscal diverso, com } \\
\text { insuficiência dos mecanismos de equalização. } \\
\text { Endividamento, restrição de autonomia e } \\
\text { dificuldades de execução orçamentária dos } \\
\text { entes subnacionais. }\end{array}$ & $\begin{array}{l}\text { Ênfase na descentralização para os } \\
\text { municípios com certa indefinição do papel } \\
\text { dos estados. } \\
\text { Número elevado de municípios e alta } \\
\text { concentração populacional. } \\
\text { Importantes desigualdades e limitadas } \\
\text { capacidades administrativas de vários } \\
\text { entes subnacionais. } \\
\text { Predomínio de competências comuns e } \\
\text { concorrentes entre os entes na área social. } \\
\text { Uniformidade de regras nacionais com pouca } \\
\text { consideração de especificidades regionais. }\end{array}$ \\
\hline
\end{tabular}

Fonte: elaboração própria. 
A implementação do SUS sem dúvida permitiu a expansão da oferta e cobertura de ações e serviços de saúde no território nacional. Porém, persiste a concentração de serviços de saúde de maior complexidade (inclusive leitos de terapia intensiva) nas regiões e cidades de maior dinamismo econômico do país 7 . Diante das importantes disparidades nas condições fiscais de estados e municípios, o enfrentamento das desigualdades socioespaciais exige um papel ativo da esfera federal no gasto social, que permanece restrito no âmbito da pandemia 8 .

Por fim, um terceiro grupo de condicionantes diz respeito à esfera da política propriamente dita. $\mathrm{O}$ acirramento das tensões políticas no contexto atual decorre de divergências de projetos políticos e disputas político-partidárias que se exacerbaram desde 2014-2016, período caracterizado pela reeleição para a Presidência de Dilma Rousseff por estreita margem em 2014, dificuldades de governabilidade em 2015-2016 e o impeachment da presidenta em 2016. O ano de 2018 foi marcado pela prisão do ex-presidente Luiz Inácio Lula da Silva e por intensas disputas eleitorais, que culminaram na eleição para a Presidência do líder de direita Jair Bolsonaro, com repercussões sobre a composição do Congresso Nacional e a eleição como governadores de alguns outsiders do sistema político (que nunca haviam disputado eleições) em alguns estados importantes da federação - tais como Rio de Janeiro, Minas Gerais, Santa Catarina - e o Distrito Federal. Por sua vez, foram eleitos governadores de oposição nos estados do Nordeste. As intensas mudanças nas coalizões políticas e na composição do primeiro escalão nos primeiros 18 meses de governo da atual gestão federal ilustram o cenário de instabilidade e conflitos no período recente, com repercussões para a política de saúde.

Mesmo nesse contexto, nos primeiros meses de enfrentamento da pandemia (fevereiro e março de 2020), o Ministério da Saúde desempenhou um papel importante, principalmente por meio da mobilização para a organização do sistema de vigilância epidemiológica sob a coordenação da Secretaria de Vigilância à Saúde e com a participação da Fundação Oswaldo Cruz, entidade vinculada ao Ministério da Saúde. O Congresso Nacional aprovou créditos orçamentários adicionais para o enfrentamento da pandemia. Em março, vários governos estaduais adotaram estratégias de enfrentamento relativas ao distanciamento social, medidas econômicas, sociais e de fortalecimento do sistema de saúde 9 , assim como alguns municípios de maior porte.

A partir de abril de 2020, no entanto, as dificuldades de coordenação no âmbito do governo federal se acentuaram - entre áreas da política e entre a Presidência e o Ministério da Saúde - culminando em duas trocas do titular do Ministério da Saúde, com repercussões sobre a composição das equipes técnicas federais. Da mesma forma, foram intensificadas as diferenças de posições entre os governos federal, estaduais e municipais em torno das medidas de enfrentamento, bem como entre governos e grupos da sociedade (comunidade científica, movimentos sociais), o que dificultou a coordenação de esforços no enfrentamento da pandemia.

As incompatibilidades de ações e de discursos levaram o Supremo Tribunal Federal a decidir por unanimidade que estados e municípios têm autonomia para a determinar medidas de isolamento social. Porém, mesmo iniciativas inovadoras como a implantação de um comitê científico de enfrentamento da COVID-19, vinculado ao consórcio dos governadores do Nordeste, e a adoção de medidas pelos Conselhos de Representação de Secretarias Estaduais e Municipais para orientar gestores e trabalhadores do SUS, permaneceram insuficientes, sem uma articulação efetiva com o governo federal.

\section{Coordenação federativa: desafios e possibilidades}

Os mecanismos de coordenação são elementos fundamentais da governança de políticas públicas em países federativos 10. Do ponto de vista formal, envolvem uma série de estratégias e instrumentos que favorecem o alinhamento de esforços e tarefas governamentais em prol de objetivos comuns.

A COVID-19 traz enormes desafios à coordenação de políticas públicas e do SUS. Em qualquer emergência sanitária, estratégias e instrumentos de coordenação visam a criar coerência entre políticas e ações, de modo a reduzir redundâncias, lacunas e contradições em tempo oportuno. Mas existem elementos próprios da pandemia de COVID-19 que também precisam ser considerados.

Os fatores que determinam os padrões de transmissão, ocorrência e mortes associados à doença são amplos e diversos, e seus impactos, atuais e futuros, afetam de modo abrangente a economia e a sociedade 11. Os efeitos da pandemia são heterogêneos e apresentam forte dimensão territorial, dado 
o importante papel dos governos subnacionais em relação às medidas de contenção, atenção à saúde, serviços sociais, e às despesas públicas, colocando-os na linha de frente da gestão da crise 12. Além disso, existem muitas incertezas quanto à dinâmica da pandemia em um cenário de profundas desigualdades, elevada carga de doença e precárias condições de vida das populações 13 .

O enfrentamento desses desafios requer coordenação entre as áreas da política pública e entre os entes governamentais. Para uma resposta abrangente e oportuna à pandemia, são necessárias ações no mínimo nos seguintes âmbitos: monitoramento detalhado da situação epidemiológica, com disponibilização ágil e transparente de informações necessárias às respostas governamentais; estratégias de comunicação claras junto aos vários grupos da sociedade; medidas de distanciamento social, para conter a transmissão do vírus e o crescimento dos casos nas diversas fases da pandemia; fortalecimento do sistema público de saúde, com articulação de ações em todos os níveis (vigilância à saúde, atenção primária, serviços de atenção às urgências e emergências e hospitais, incluídas as unidades de terapia intensiva); ações de apoio à economia e ao emprego; medidas de proteção social, especialmente voltadas às populações em situação de maior vulnerabilidade social e aos grupos mais atingidos pela doença. Diante do quadro de recessão mundial provocado pela pandemia, acrescente-se a necessidade de ações em médio e longo prazos voltadas à recuperação econômica e melhoria das condições de infraestrutura (habitação, saneamento), de vida e de saúde das populações em países marcados por desigualdades, como os latino-americanos.

Em face do caráter continental, diverso e desigual do Brasil, o conjunto de estratégias pode ser variado entre regiões, estados e municípios. Porém, dadas as características da federação brasileira, a variedade de respostas requer um papel ativo do governo federal e intensa cooperação entre esferas de governo nos âmbitos nacional e estadual, e em múltiplas escalas regionais.

\section{Considerações finais}

Em um país federativo, imenso e desigual como o Brasil, a coordenação de políticas entre áreas e esferas de governo é fundamental para potencializar a resposta do Estado à emergência sanitária. Estratégias diversas e articuladas são necessárias para evitar que a doença se propague em sucessivas ondas no território nacional, prolongando a duração da pandemia e suas consequências econômicas, sociais e humanitárias, considerando-se o grande número de vidas perdidas, o sofrimento para milhares de famílias e o potencial de desestruturação do tecido social diante de uma crise complexa e multifacetada.

No Brasil, esse processo é tensionado por uma série de condicionantes que constrangem a atuação federativa do Estado. Nesse contexto, permanecem enormes desafios para o fortalecimento da coordenação no que tange à conformação de estruturas de comando e articulação entre diferentes organizações, a repartição clara de responsabilidades e competências gestoras entre os entes e o aprimoramento de mecanismos de cooperação intergovernamental, entre setores da política pública e com os diferentes grupos da sociedade, no controle da COVID-19. 


\section{Colaboradores}

Todas as autoras contribuíram com a concepção, redação do artigo e revisão crítica do texto.

\section{Informações adicionais}

ORCID: Luciana Dias de Lima (0000-0002-06408387); Adelyne Maria Mendes Pereira (0000-00022497-9861); Cristiani Vieira Machado (0000-00029577-0301).

\section{Referências}

1. Our World in Data. Coronavirus pandemic (COVID-19). https://ourworldindata.org/ (acessado em 23/Jun/2020).

2. Abrucio FL. Reforma política e federalismo: desafios para a democratização brasileira. In: Benevides MV, Kerche F, Vannuchi P, organizadores. Reforma política e cidadania. São Paulo: Editora Fundação Perseu Abramo; 2003. p. 225-65.

3. Almeida MHT. O Estado no Brasil contemporâneo. Um passeio pela história. In: Melo CR, Sáez MA, organizadores. A democracia brasileira. Balanço e perspectivas para o século 21. Belo Horizonte: Editora UFMG; 2007. p. 17-37.

4. Arretche M. Democracia, federalismo e centralização no Brasil. Rio de Janeiro: Editora FGV/ Editora Fiocruz; 2012.

5. Noronha KVMS, Guedes GR, Turra CM, Andrade MV, Botega L, Nogueira D, et al. Pandemia por COVID-19 no Brasil: análise da demanda e da oferta de leitos hospitalares e equipamentos de ventilação assistida segundo diferentes cenários. Cad Saúde Pública 2020; 36:e0115320.

6. Região e Redes. O planejamento regional é estratégico no enfrentamento da pandemia da Covid-19. Novos Caminhos 2020; (18). http:// www.resbr.net.br/o-planejamento-regional-eestrategico-no-enfrentamento-da-pandemiada-covid19/\#.XvKT4WhKjIW.

7. Portela MC, Pereira CCA, Lima SML, Andrade CLT, Soares FRG, Martins M. Limites e possibilidades dos municípios brasileiros para o enfrentamento dos casos graves de COVID-19. Nota Técnica 1. https://portal.fiocruz.br/sites/ portal.fiocruz.br/files/documentos/nt_1_por tela_et_al_limites_e_possibilidades_dos_mu nicipios_brasileiros_na_covid-19_1.pdf (acessado em 23/Jun/2020).

\section{Agradecimentos}

L. D. Lima e C. V. Machado são bolsistas de produtividade e agradecem ao Conselho Nacional de Desenvolvimento Científico e Tecnológico (CNPq) o apoio recebido para o desenvolvimento de estudos sobre o tema.

8. Tesouro Nacional Transparente. Monitoramento dos gastos da União com combate à COVID-19. https://www.tesourotransparente. gov.br/visualizacao/painel-de-monitoramen tos-dos-gastos-com-covid-19 (acessado em 23/ Jun/2020).

9. Freitas CM, coordenador. A gestão de riscos e a governança na pandemia por COVID-19 no Brasil. Análise dos decretos estaduais no primeiro mês. Relatório técnico e sumário executivo. https://portal.fiocruz.br/sites/portal.fio cruz.br/files/documentos/relatoriocepedesisolamento-social-outras-medidas.pdf (acessado em 23/Jun/2020).

10. Souza CM. Coordenação, uniformidade e autonomia na formulação de políticas públicas: experiências federativas no cenário internacional e nacional. Cad Saúde Pública 2019; 35 Suppl 2: e00046818.

11. Werneck GL, Carvalho MS. A pandemia de COVID-19 no Brasil: crônica de uma crise sanitária anunciada. Cad Saúde Pública 2020; 36:e00068820

12. Organisation for Economic Co-operation and Development. The territorial impact of COVID-19: managing the crisis across levels of government. Paris: Organisation for Economic Co-operation and Development; 2020.

13. Barreto ML, Barros AJD, Carvalho MS, Codeço CT, Hallal PRC, Medronho RA, et al. O que é urgente e necessário para subsidiar as políticas de enfrentamento da pandemia de COVID-19 no Brasil? Rev Bras Epidemiol 2020; 23:e200032. 
Lima LD et al. 